\title{
América Latina y los orígenes de la lógica jurídica*
}

Domingo García Belaunde

El tema que aquí se pretende desarrollar es extenso y problemático. A tal extremo que, existiendo numerosas investigaciones puntuales, no hay, hasta donde alcanza mi información, un tratamiento que abarque la problemática en su integridad. De ahí mi interés en hacer una aproximación global, necesariamente sumaria, que sirva de marco introductorio al estudio de la lógica jurídica en nuestra América, en su fase inicial. Y esto requiere algunas concesiones a favor del lector no especialista. Con estas aclaraciones, daremos curso a nuestro planteo.

\section{Lógica y lógica jurídica}

Como se sabe, la lógica encuentra su punto de partida en Aristóteles, que él no llamó así, sino Analítica, y que desarrolló en un libro que luego se conoció como Organon. Por cierto, esto no quiere decir que antes del Estagirita no existiese especulación lógica. Pero en términos generales, a él se le reconoce como el padre de la lógica, y así lo entendemos aquí.

A partir de él, se inicia un largo período en el cual su influencia va a ser definitiva. Lo que no significa que no existiesen con posterioridad, avances e investigaciones notables (como es el caso de la Stoa). Pero lo cierto es que la lógica aristotélica tendrá una influencia decisiva, y así hasta Kant, que no vaciló en declararla como una ciencia acabada, es decir, perfecta, pues no sólo no había avanzado un sólo paso, sino que ya no avanzaría uno más. La enfática declaración de Kant era válida en su

\footnotetext{
Ponencia presentada a la Sociedad Peruana de Filosofía.
} 
momento y el pensador de Köenisberg no podía imaginar que otros antes que él, como Leibniz, habían hecho avances notables. Pero las aportaciones de Leibniz permanecieron inéditas y sin explorar, por lo que el nuevo giro de la lógica se dará recién en el siglo XIX, en especial con la obra de Boole, De Morgan y Frege.

Por tanto, podemos decir que, en cierto sentido, las cosas cambian en el siglo XIX. Por tal motivo, se acostumbra clasificar a la lógica en:

a) tradicional, que va desde Aristóteles hasta el siglo XIX, y,

b) clásica, desde el siglo XIX hasta nuestros días.

Si esto lo conectamos con el derecho, vemos que el pensamiento lógico siempre estuvo cerca del mundo jurídico. No son escasos los textos que tratan de lógica jurídica, desde los jurisconsultos romanos hasta los racionalistas del siglo XVIII. Por tanto, existiendo una lógica general, era fácil extenderla al análisis normativo, resultando así una lógica aplicada al derecho. Y así fue utilizada durante siglos.

Sin embargo, lo que hay que señalar es que la lógica actual, la que se cultiva hoy en día, no es la lógica tradicional, sino la lógica clásica, nacida en el siglo XIX. Esta lógica, que ha supuesto avances notables en un siglo, representa en sustancia, la utilización de la matemática para el análisis del raciocinio, y por eso, se le llama lógica matemática, lógica formal, logística o lógica simbólica (por utilizar una serie de símbolos, que son artificiales, y que en consecuencia, tienen un mayor grado de precisión). Por tanto, lo que interesa, hoy por hoy, es la lógica matemática, nacida con propiedad en el siglo XIX.

Conforme señalan gran cantidad de estudiosos, la relación entre lógica tradicional y lógica clásica es lineal, toda vez que la segunda no representa una negación de la primera, sino su superación en sentido hegeliano. Dicho en otras palabras, la lógica tradicional sigue siendo válida, pero se ha convertido en un capítulo muy pequeño de la lógica clásica.

A su vez, desde la década de los treinta de este siglo, y más en concreto, desde los cincuenta y a partir de la lógica clásica, se han desarrollado una serie de lógicas heterodoxas con respecto a aquélla, que son conocidas como lógicas no clásicas. Esto es, lógicas que partiendo de la estructura de la lógica clásica, avanzan más allá, jugando con valores o modalidades distintas. Pero esto en fecha relativamente reciente, y desde el arsenal de la lógica clásica. O si se quiere, como variantes de ésta. 


\section{2. ¿Cuál de las lógicas jurídicas?}

Como queda dicho, la utilización de la lógica tradicional en el derecho, fue frecuente. Pero esta lógica, siendo útil, fue poco desarrollada. Aún más, desde el siglo XIX es rebasada por la lógica clásica, que la asume, la supera y la proyecta en niveles superlativos.

Pero el hecho de que se haya desarrollado grandemente la lógica simbólica, no significa que ésta hubiese sido aplicada al derecho. Por el contrario, la lógica tradicional seguía utilizándose en el ambiente jurídico, y en realidad rendía sus frutos al jurista. Así, en muchas de nuestras latitudes, los juristas se esmeraban en aplicar la lógica tradicional, e incluso algunas variantes que surgían de la fenomenología husserliana. Y esto todavía se observa en determinados círculos académicos.

Sin embargo, la nueva lógica aplicada al derecho, se va a dar solamente en 1951, como lo demostraremos más adelante. Esto es, si bien la lógica tradicional existió desde Aristóteles y aún antes, y además los juristas la utilizaron (en el fondo, el corpus juris civilis trasunta una arquitectónica lógica), lo cierto es que cuando se desarrolla la lógica simbólica (es decir, la lógica clásica), los juristas no se dan por enterados y siguen usando la lógica tradicional. El encuentro ocurre en fecha muy posterior: en 1951.

Pues bien, en este año, se dió un notable evento cultural en el Perú, pues se llevó a cabo el Congreso Internacional de Filosofia, en la sede de la Universidad de San Marcos, precisamente para conmemorar el cuarto centenario de su fundación. Asistieron a ella filósofos notables, y también muy destacados filósofos del derecho latinoamericano, entre los cuales se encontraban dos grandes figuras: el mexicano Eduardo García Máynez y el argentino Carlos Cossio. Ellos coincidieron aquí con el lógico peruano Francisco Miró Quesada C.

\section{El encuentro de 1951}

El pensamiento de Kelsen era conocido muy ampliamente desde la década del treinta, en el ambiente jusfilosófico de habla castellana. Contribuyeron a ello las conocidas traducciones y estudios de Legaz Lacambra y Recaséns Siches. Luego se traduciría la Teoría Pura del Derecho, con prólogo de Carlos Cossio (en Buenos Aires y en 1941), en donde el famoso jusfilósofo argentino declaró que la Teoría Pura del Derecho, no era más que lógica jurídica formal, acorde con su especial configuración jusfilosófica. Esta tesis de Cossio, tuvo mucho predicamento en el mun- 
do hispánico (España incluída), y llegó a oídos del propio Kelsen, quien desautorizó la especie. Aún más, Kelsen, en esa época, estaba convencido de que la única lógica existente y válida era la aristotélica. Por otro lado, otra gran figura jusfilosófica, Luis Recaséns Siches, con un pensamiento vitalista propio (influencias de la fenomenología y del vitalismo orteguiano), no tomó parte en la discusión, pero ella le serviría para desarrollar, a la altura de 1956, su lógica de lo razonable, que era algo al margen de la lógica de lo racional o simbólica.

Por su lado, Eduardo García Máynez había polemizado con Cossio años atrás, y se aprestaba a preparar su introducción a la lógica jurídica que publicaría ese mismo año. Otras importantes figuras en nuestro ámbito jusfilosófico, eran Llambías de Azevedo (que no se interesó por el tema); Jorge Millas, que algo conocía de la nueva lógica, pero que no publicaría nada hasta 1954 y en forma por demás esquemática. Y Miguel Reale, en el Brasil, que tenía otros derroteros, y que entonces no era conocido en los países de habla castellana.

Ese era el ambiente en América Latina en 1951. Veamos ahora que pasó en el Congreso.

\section{Un planteamiento radical}

En el referido Congreso, Miró Quesada presentó una ponencia que tituló La lógica del deber ser y su eliminabilidad, que circuló profusamente a mimeógrafo, y fue muy citada por varios autores, pero que sólo se publicó en letra de imprenta en 1972. El planteo de esta ponencia, era, en síntesis, el siguiente:

i. La lógica jurídica, si existe, tiene que ser una teoría de la deducción;

ii. Para hacer lo anterior, hay que aplicar la lógica simbólica al derecho positivo;

iii. Esto no se ha hecho hasta ahora;

iv. El primer problema grave que hay que dilucidar es el de las proposiciones, su significado, y su relación con las normas (de las que no cabe decir que sean verdaderas o falsas).

La tesis de Miró Quesada era radical, tal como fue sostenida en julio de 195l. Lo más curioso es que, a esa fecha, García Máynez tenía publicado un libro de introducción a la lógica jurídica y el mismo Cossio, 
como fruto inicial de un seminario sobre lógica jurídica llevado a cabo en la Universidad de Buenos Aires, había dado a la estampa un ensayo sobre lo mismo.

Ahora bien, para hacer lógica jurídica -admitiendo que esto sea posible- era necesario tener dos condiciones:

a) Saber lógica, y

b) Saber derecho.

Kelsen no había hecho lógica jurídica porque no creía en ella, por lo menos, en aquel entonces. Los dos que habían intentado hacerlo, a ese momento, eran García Máynez y Carlos Cossio.

\section{El intento de García Máynez}

El libro de García Máynez había llegado a Lima cuando se inaugura el Congreso, motivo por el cual Miró Quesada lo cita en su ponencia. Se trata de un esfuerzo que, por cierto, era meritorio. Más aún si tenemos en cuenta que ese era sólo el primer jalón de una larga investigación. Pero en realidad, García Máynez, a esa época, no sabía lógica: por lo menos, no sabía lógica matemática. Si revisamos el libro ligeramente, nos podremos dar cuenta de que esto es así. Él mismo nos dice que toma como referencia el libro de Pfänder sobre Lógica, que tuvo gran influencia en la época. Aún más, visto a trasluz, el esquema de Pfänder es trasladado por García Máynez al derecho, y proyecta, sobre esa base, su producción futura.

Poco después, García Máynez se pone a estudiar lógica matemática, utilizando precisamente el manual de Miró Quesada -entre otros- y publica algo más sólido en 1953. Luego emprenderá la publicación de una impresionante trilogía: Lógica del juicio jurídico (1955), Lógica del concepto jurídico (1959) y Lógica del raciocinio jurídico (1964). Así, García Máynez cerró el ciclo y creó un verdadero sistema de lógica jurídica, si bien muy personal y además con poca influencia, ya que él no considera la deducción como básica de la lógica, sino sólo como uno de sus capítulos.

\section{El intento de Cossio}

Cossio fue, sin lugar a dudas, uno de los sorprendidos por los esquemas 
que Miró Quesada dibujaba en la pizarra, durante una de las sesiones del Congreso. Es probable que eso le haya causado desazón. En todo caso, Cossio tenía una formación kantiana y sobre todo fenomenológica, y su concepto de la lógica era distinto y ajeno a los simbolismos que Miró Quesada manejaba. Con posterioridad, Cossio ha alegado que él tenía en ese momento una noción clara de la novísima lógica deóntica, y aún más, ha aprovechado la oportunidad para disputarle honores a von Wright, a raíz de las conferencias que éste último impartiera en la Universidad de La Plata en 1968. Esto, por cierto, es algo debatible. Pero en 1951, cuando se da el encuentro de San Marcos, Cossio no tenía una idea clara de las cosas que ahí se debatieron. Si intentó hacerlo más adelante, o si su lógica era otra muy distinta, como después lo ha sostenido en correspondencia que conservo, es algo de por sí interesante, pero que no ha dado fruto alguno. Esto es, aparte de algunos escarceos (como denominar Lógica del deber ser, a lo que hoy se conoce como "lógica normativa"), Cossio no ha dejado nada sobre lógica jurídica, que sea rescatable. Lo cual no quiere decir que no haya tenido y tenga un gran valor dentro de la filosofía jurídica de la región. Cossio es notable por muchos conceptos, pero no creo que lo sea en este punto.

Más bien, si analizamos con calma el texto de Cossio de 1951, y el programa que desarrolló en aquel entonces en un seminario que dirigía en Buenos Aires, vemos que en realidad Cossio estaba bregando, fuertemente, por construir una lógica jurídica, pero partiendo de Husserl. En efecto, si el mismo Husserl, que partió de la fenomenología para llegar a la lógica, no pudo ir muy lejos (como lo demostraron los trabajos de su discípulo Pfänder) era más que improbable que Cossio pudiese dar ese gran salto. Esto es, tenía un punto de partida tradicional, y en consecuencia, le era muy difícil formular una lógica jurídica moderna.

\section{Otros intentos en la región}

La década del cincuenta es realmente rica en el desarrollo del pensamiento jurídico. Y con independencia a lo señalado, vale la pena mencionar otros esfuerzos hechos por la misma época en la América Latina. En primer lugar, a Jorge Millas, mencionado por Miró Quesada y García Máynez, pero que de la información que tenemos disponible, no creemos que haya avanzado gran cosa, y en todo caso, ello es posterior a 1951. Además, su obra se encarriló luego por otros senderos, y en donde lo lógico-jurídico ocupa un lugar secundario y de poca importancia. 
Otro pensador interesante, es el guatemalteco Héctor NeriCastañeda, que incursiona con trabajos pioneros, pero en el medio académico norteamericano. Sólo en 1957 se dará a conocer ampliamente en el mundo latinoamericano. Neri-Castañeda seguirá esta veta y la desarrollará ampliamente durante toda su vida.

Finalmente, recordemos a Recaséns Siches y su lógica de lo razonable, que es de 1956, y que difunde y amplía durante largos años. Recaséns en parte es opositor de la lógica simbólica y en parte es defensor de la separación entre ambas. Y su postura es interesante, pues su planteo tiene mucho predicamento hoy, desde el punto de vista de enfoques relacionados con la racionalidad práctica, la hermenéutica, la teoría de la argumentación, la tópica, etc.

\section{El panorama europeo: Klug}

Lo más curioso del caso es que, al mismo tiempo que en Lima se daba ese gran debate, y tenía eco en el resto del continente, en Alemania, un joven abogado con formación lógica, publicó un libro sobre Lógica juridica (1951) que ha tenido mucho éxito, y que fue traducido al castellano años después. Su autor, Ulrich Klug, discípulo de Hilbert, utilizó la lógica clásica y la aplicó, tal cual, al mundo del derecho. Dicho en otra forma: preparó un manual de lógica matemática, y demostró con numerosos ejemplos de los códigos civil y penal alemanes, que la lógica era útil para el jurista y para su manera de razonar. No se planteó los problemas teóricos de la disciplina; pero al mismo tiempo que señalar los límites del pensar lógico, demostró que la lógica servía perfectamente al operador del derecho. Y lo hizo en un libro orgánico que publicó, como queda dicho, en 1951.

Esto lo convierte, sin lugar a dudas, en el fundador de la lógica jurídica a nivel mundial, y por eso es que ameritamos más aún el encuentro sanmarquino y la labor pionera de Miró Quesada.

\section{El panorama europeo: von Wright}

En el mismo año, y en una revista londinense (Mind), Georg H. von Wright publica un breve artículo de quince páginas, en el que pone las bases de una lógica deóntica, esto es, una lógica que jugase, por así decirlo, no con los valores de verdad y falsedad (como hacía la lógica clásica y por cierto Klug), sino con otras categorías, como Obligatorio, Pro- 
hibido, Permitido e Indiferente. Estas eran modalidades y se aplicaban a las disciplinas normativas; o sea, a todas aquellas que estudiaban normas, pero preferentemente a la moral, que fue la gran preocupación de von Wright.

Según ha contado recientemente en una entrevista, von Wright conoció personalmente a Kelsen en Finlandia en 1952, y sólo más tarde se puso a estudiar derecho, que fue objeto de sus reflexiones tan sólo en su libro Norma y Acción, de 1963. Esto es, von Wright pensó en crear una nueva lógica para explicar mejor las normas morales; no las normas jurídicas, que no conocía y seguramente ni le interesaban. Sin embargo, la idea de von Wright, y de quienes han seguido sus huellas, es que existe una lógica deóntica, como rama de la lógica modal, dentro de la cual cabe el análisis del discurso jurídico.

El problema con von Wright es que, desde 1951, ha dado tantas vueltas teóricas, que es dificil seguirlo, pues su sistema o enfoque general, lo cambió al poco tiempo y luego ha seguido así con velocidad de caleidoscopio. Sin embargo, los estudios de lógica deóntica han crecido de manera espectacular, y todos ellos reconocen al lógico finés como el iniciador de la disciplina, que ha prestado gran ayuda a la filosofía del derecho (en especial, para afinar sus principales aspectos teóricos).

\section{Intermezzo}

Sin lugar a dudas, Klug es el creador moderno de la lógica jurídica. Y al lado de él, podemos colocar a Miró Quesada. Pero anotemos varios aspectos relacionados con este aserto.

En primer lugar, el enfoque de Klug, si bien pionero e interesante, y con seguimiento en Alemania, no es el que tenga mayor predicamento en la comunidad lógica mundial.

En segundo lugar, es más bien el enfoque de von Wright, el que ha despertado más seguimientos, si nos atenemos a su repercusión y, sobre todo, al número de publicaciones existentes.

Por cierto, para los seguidores de von Wright, no existe la lógica jurídica: lo que existe es una lógica déontica (o lógica normativa), que es muy distinto.

Finalmente, el más acertado en plantear la lógica jurídica en América Latina, fue Miró Quesada, pero luego de algunos ensayos, abandonó el campo. Y si volvió a él, fue tan sólo para intentar nuevos enfoques, que no han anclado en nada definitivo. Miró Quesada es un pionero $y$, sobre todo, un gran incitador, pero no ha logrado rematar 
su obra. Además, lo jurídico es algo marginal dentro de su extensa producción.

En realidad, el primer esfuerzo armónico, sistemático y logrado de la lógica jurídica en América Latina, es el de García Máynez, como ya lo hemos señalado. Pero no obstante su interés, ha seguido anclado en ciertas tendencias heredadas de la lógica fenomenológica, y tampoco ha tenido continuadores.

\section{El futuro de la lógica jurídica}

Lo que tenemos hoy es una lógica jurídica que parte del cálculo proposicional (en la línea de Klug), y una lógica deóntica (o lógica normativa) interesada por lo jurídico, fundada por von Wright. En ambas tendencias han habido frutos, si bien la segunda es, cualitativamente, más significativa que la primera. Pero lo que nos preguntamos es qué futuro puede tener una lógica así, en cualesquiera de sus dos versiones.

En su texto fundacional, Klug llegó a afirmar que la lógica no agotaba el repertorio del derecho, y que en éste, cra muy importante la intuición. En fecha más reciente, von Wright ha reconocido que puede haber distintos enfoques para la comprensión del derecho, en los cuales la lógica deóntica es poco útil, y en algunos campos, prácticamente no sirve (como en el problema hermenéutico).

$\mathrm{Y}$ es que, como lo han señalado algunos autores, la aplicación de la lógica a la actividad humana, es tarea muy ardua y da pocos frutos. Que es en el fondo lo que ha pasado con las discusiones, paradojas y avances poco significativos, que ha tenido la lógica deóntica desde su creación.

Adicionalmente, y en el mundo de la práctica, el abogado, el juez, el profesor, el jurista, esto es, el operador del derecho, juega con una lógica implacable, que le viene de su formación universitaria, ya que el derecho tiene una construcción arquitectónica. Si a eso se le añade, conocimientos elementales de la lógica clásica (en especial, el cálculo de predicados), le será más que suficiente. Se trata, pues, de un instrumento útil, pero dentro de sus propios límites.

Por tanto, nuestra opinión es que, salvando su alto nivel teórico y su dignidad académica, la lógica aplicada al derecho (sea proposicional o deóntica), brinda al jurista servicios bastante modestos. 


\section{Apéndices}

\section{I.- Bibliográfica}

Sobre el tema que trata este trabajo, existe una literatura inmensa, si bien toda ella es fragmentaria y puntual.

A fin de hacer más fácil la lectura de este texto, he reservado para este apartado una bibliografía de apoyo, centrada en lo básico, que a su vez remite a otra bibliografía especializada, que pueden consultar los que tengan interés en profundizar el tema. Y por cierto, centrada en el período inicial que nos ocupa, que va de 1951 a 1957.

Sobre lógica en general, existen infinidad de manuales, escritos directamente en castellano o en traducciones de otros idiomas. Entre esa multitud, creemos que para una información panorámica, especialmente útil al hombre de derecho, es la Introducción a la lógica de Irving $M$. Copi, con múltiples ediciones y reimpresiones, tanto en castellano como en inglés. La última versión castellana, proveniente de la octava edición en inglés, tiene la ficha siguiente: Introducción a la lógica, por I.M.Copi y Carl Cohen, editorial Limusa, México 1995; con la peculiaridad de que al final trae un capítulo dedicado a la lógica y al derecho, de sumo interés.

Sobre la lógica clásica, el manual de Alfredo Deaño Introducción a la lógica formal, Alianza Universidad, (Madrid, varias ediciones), es muy valioso, en especial para quien viene del campo de las humanidades. La pequeña Introducción a la lógica contemporánea de R. Blanché (ediciones Lohle, Buenos Aires 1963) tiene el mérito de dedicar un amplio panorama a las lógicas no clásicas. Por cierto, sobre cada una de estas lógicas existen manuales, antologías o ensayos en gran cantidad.

Tarski afirma que la lógica moderna es ciencia deductiva y que la lógica tradicional es sólo una parte de la nueva, que, en conjunto, es pequeña y en cierto sentido insignificante (cf. su Introduction to logic and to the methodology of deductive sciences Oxford Univ. Press, New York 1970, pp XIII y 19). Esta afirmación de uno de los más grandes lógicos contemporáneos, es un criterio pacífico entre los especialistas.

Sobre la historia de la lógica, existe una amplia literatura. Dos obras notables, son las de Bockenski Historia de la lógica formal, edit. Gredos, Madrid 1966 (con numerosos textos), y la de W. y M. Kneale El desarrollo de la lógica, edit. Tecnos, Madrid 1972. Ambas son útiles, aún cuando muy extensas. 
Una muy breve historia de la lógica, hecha con fuentes de primera mano, puede verse en La lógica simbólica de E. Agazzi, edit. Herder, Barcelona 1967. Lo valioso del libro de Agazzi, no es sólo su amplitud de miras, sino la inclusión de algunos problemas metateóricos y una muy amplia parte dedicada a la historia de la lógica (los manuales de lógica, por lo general, dejan de lado la parte histórica, sobre todo, el período anterior al siglo XIX). Ahí se podrán ver aspectos de la lógica aristotélica y algunas de las contribuciones posteriores, con una amplia bibliografia de referencia.

Sobre el Congreso Internacional de Filosofía de San Marcos (julio de 1951), debemos lamentar que no haya actas ni publicaciones al respecto. Tan sólo la revista Mercurio Peruano (núm. 292, julio de 1951) dió noticia del evento, publicando algunas de sus ponencias. Recientemente, ha hecho referencia a él, David Sobrevilla en La Filosofía contemporánea en el Perú, Carlos Matta editor, Lima 1996, pp. 150 - 151.

De Francisco Miró Quesada, cf. especialmente su libro Ensayos de filosofía del derecho, Universidad de Lima, Lima 1986, que contiene sus principales contribuciones. Su ponencia de 1951 titulada La lógica del deber ser y su eliminibilidad, texto mimeografiado, 5 pp., se reprodujo por vez primera en 1972, y luego en el volumen antes citado (Estudios....). En 1953, Miró Quesada terminó un libro: Bases y lineamientos de la lógica jurídica, texto mecanografiado de 300 pp., que ha permanecido inédito como totalidad. Este libro tenía cuatro partes: la primera dedicada a discutir la posibilidad de esta lógica; la segunda, a explicar los principios básicos de la lógica moderna; la tercera, a analizar la estructura de la proposición jurídica; y la cuarta parte a desarrollar un sistema de lógica jurídica.

De éstas, han sido publicadas, en primer lugar, la primera, titulada «Problemas fundamentales de la lógica jurídica» (en Revista de Derecho y Ciencias Politicas, 1954), con la cual su autor se graduó de Bachiller en Derecho en la Universidad de San Marcos, y posteriormente y con adendas, en forma de libro y en 1956 (en la Biblioteca de la Sociedad Peruana de Filosofía).

A la segunda parte le dió un tratamiento distinto, y la publicó como libro: Iniciación lógica, Universidad de San Marcos, Lima 1958 (hay una segunda edición de 1963).

La tercera está publicada, parcialmente: «El formalismo y las ciencias normativas» en «Diánoia», núm. 2, 1956. La cuarta y última parte, algo reducida, la publicó con el título «Teoría de la deducción jurídica» en «Diánoia», núm. 1, 1955, 
Posteriormente, publicó su ensayo «Consideraciones generales sobre el concepto de lógica jurídica» en Estudios en honor del Dr. Luis Recaséns Siches, UNAM, México 1980, tomo I, y finalmente "Lógica jurídica idiomática» en Conferencias do III Congreso brasileiro de filosofia juridica e social, Paraíba 1988, en donde replantea su anterior concepción.

Sobre Miró Quesada, puede verse, Fernando Bobbio La lógica juridica de F. Miró Quesada, Lima 1969, Tesis de Bachiller en Derecho en la Universidad de San Marcos, y, en especial, Lógica, razón y humanismo (La obra filosófica de Francisco Miró Quesada C.), Universidad de Lima 1992, editado por David Sobrevilla y D. García Belaunde, con la colaboración de varios autores. Aquí Sobrevilla analiza el pensamiento lógico-jurídico de Miró Quesada hasta 1986, con anotaciones críticas y bibliografia; Roberto J. Vernengo se ocupa de la etapa posterior.

De Eduardo García Máynez tenemos: Introducción a la lógica juridica, Fondo de Cultura Económica, México 1951; y especialmente su tratado de lógica del derecho desarrollado en tres partes: Lógica del juicio jurídico, FCE, México 1955, Lógica del concepto jurídico, FCE, México 1959 y Lógica del raciocinio jurídico, FCE, México 1964. Además, Ensayos filosófico-jurídicos, Universidad Veracruzana, Xalapa 1959, en donde recoge diversos aportes suyos, en especial, sus importantes contribuciones lógicas a partir de 1953. Al ingresar al Colegio Nacional en 1958, García Máynez dió, sin querer, las razones de porqué el hombre de derecho, práctico por excelencia, no gusta de las especulaciones lógicas. Dijo así: «El asunto, por su aridez, resulta poco atractivo. Los territorios de la lógica son comarcas desoladas, cuya belleza -si la tienenes la serena y fría de un paisaje polar» (Ensayos, cit. p. 341).

Un resumen de su obra lo ha ofrecido García Máynez en la voz «Lógica jurídica» en Enciclopedia Juridica Omeba, tomo XVIII. Veáse también, Jesús A. Fernández Suárez, La filosofía juridica de Eduardo García Máynez, Universidad de Oviedo, 1991.

De Carlos Cossio, cf. «Las posibilidades de la lógica jurídica según la lógica de Husserl», en Revista de la Facultad de Derecho y Ciencias Sociales, Universidad de Buenos Aires, 1951; reeditado con ligeras variantes con el título «La norma y el imperativo en Husserl» en Revista Brasileira de Filosofia, 10, 1969, y en otras publicaciones.

Igualmente, «La Lógica jurídica formal según la concepción egológica» en La Ley, 20 de marzo de 1959, y "La lógica jurídica y su denominación", en Revista de la Facultad de Derecho de México, núm. 87-88, 1973. Sobre Cossio, ver Manuel Atienza, La filosofia del derecho argentina actual, Depalma, Buenos Aires 1984. 
De von Wright, cf. «Deontic logic» en Mind, vol. LX, num. 237, january 1951 y $A n$ Essay in modal logic, Amsterdan 1951 (hay versión castellana); Norma y acción, edit. Tecnos, Madrid 1976 (la versión original es de 1963). Entre la numerosa bibliografia posterior, cf. An essay in deontic logic and the general theory of action, Amsterdan 1968. Un gran panorama, cf. «Entrevista a Georg H. von Wrigth», por Eugenio Bulygin, en Doxa, núm. 12, 1992.

De Jorge Millas, cf. «Las dos clases de proposiciones en la ciencia del derecho» en Anales de la Facultad de Ciencias Jurídicas y Sociales, Universidad de Chile, 1-3, 1952-1954. Y el Anuario de Filosofia jurídica y Social, núm. 2, 1984, Estudios en memoria de Jorge Millas.

De Héctor Neri-Castañeda, cf. «Un sistema general de lógica normativa» en Diánoia núm. 3, 1957 (que resume trabajos anteriores). Su última obra importante es Pensar y hacer, UNAM, México 1993.

El libro de Klug fue traducido por García Bacca y publicado por la Universidad Central de Venezuela en Caracas y en 1961 (hay otra traducción hecha sobre una edición posterior publicada por Témis, en Bogotá).

Por esa época, Juan David García Bacca publicó sus «Planes de lógica jurídica» en Studia Iuridica, núm. 2, 1958. García Bacca es autor de un pequeño manual de lógica moderna publicado en 1936 (Edit. Labor, Barcelona), el primero en castellano. El primero escrito directamente en castellano en América Latina es el de Francisco Miró Quesada (Lógica, Lima 1946).

Recaséns Siches inicia su vasta producción en este punto, con Nueva fillosofía de la interpretación del Derecho, F.C.E., México 1956 (hay ediciones posteriores), en donde desarrolla por vez primera su «lógica de lo razonable».

Si bien la lógica jurídica se ha desarrollado al margen de Kelsen, éste ha proporcionado la materia prima de numerosas discusiones. Su interés por la lógica aplicada al derecho se nota recién a partir de 1960 ( $\mathrm{La}$ dottrina pura del diritto, Enaudi, Torino 1966, que traduce el original alemán con anotaciones hechas epistolarmente por el autor al traductor, M.G. Losano), y en su artículo «Law and logic» (en H. Kelsen Essays in legal and moral philosophy, Reidel Pub. Co. 1973), que refleja sus inquietudes últimas y su correspondencia con Klug.

Referencia que cubre este período, cf. Norberto Bobbio, «Derecho y lógica» y Amadeo G. Conte "Bibliografía de lógica jurídica (1936- 
1960)", ambos en el Cuaderno núm. 18, UNAM, México 1965 y Luis Legaz Lacambra «El problema de la lógica jurídica en algunas obras recientes", en Anuario de Filosofía del Derecho, tomo II, 1954. Utiles datos pueden encontrarse en Roque Carrión Wam «Bibliografía de lógica jurídica» en Derecho (Lima), núm. 29, 1971.

Un gran panorama, para quien desee asomarse a lo reciente, cf. Lógica, edición de Carlos E. Alchourrón, Editorial Trottas, Madrid 1995, que contiene un capítulo sobre lógica deóntica de Eugenio Bulygin.

También Roberto J. Vernengo, "Derecho y Lógica: un balance provisorio" en Liberdade, participaçao comunidade, Anais do II Congreso Brasileiro de Filosofía jurídica e Social, Sâo Paulo 1986; Georges Kalinowski "Lógica del diritto» en Enciclopedia del Diritto, tomo XXV, Giuffré, Milano 1975 y Manuel Manson, Filosofía, Derecho y Lógica, Santiago de Chile 1996.

\section{Cossiana}

La primera vez que envié una carta a Carlos Cossio fue en 1971, para pedirle una copia de la ponencia de Francisco Miró Quesada presentada en el Congreso de 1951, titulada «La lógica del deber ser y su eliminabilidad». Como demoraba en contestarme, solicité a mi amigo el prof. Roque Carrión, que insistiese sobre lo mismo, ya que él lo veía con cierta frecuencia en Buenos Aires. Fue así que copia de la ponencia fue remitida por Cossio a Carrión, y publicada en 1972, con una nota mía, en la revista Derecho órgano de la Facultad de Derecho de la Pontificia Universidad Católica del Perú. Años más tarde, le volví a escribir, esta vez para pedirle otra de las ponencias que Miró Quesada había presentado a ese mismo Congreso, y que su autor daba por perdida. Para entonces, ya Cossio había leído la ponencia de Miró Quesada publicada en 1972, así como la nota mía y el post scriptum que el mismo autor agregó para esa ocasión. Fue así que Cossio no vaciló en contestarme, y aprovechar la ocasión para hacer una larga digresión sobre el famoso encuentro de 1951, en la cual da además su propio punto de vista sobre la lógica jurídica, y que ahora reproduzco, pues es importante por lo que dice y por cuanto aclara mejor aún el panorama de esos años. Tiempo después conocí personalmente a Cossio, y luego lo visité varias veces mientras vivía. Cossio se me presentó como un hombre más bien bajo; de gestos vivaces, de tez muy clara y andar ligero. Gran conversador, era bueno y cordial en exceso, sobre todo cuando estaba al frente con gente más joven. Pero en el fondo, me dí cuenta que era un hombre muy polémico y tremendamente apasionado, que en la vida diaria del trajín discipular, debió haber sido muy difícil. En lo personal, guar- 
do un grato recuerdo de Cossio, cuyas principales obras leí por esa época, pero hoy, a la distancia, me parece que ellas pertenecen a un pasado, interesante, pero definitivamente concluído.

El texto es el siguiente:

B.A., 2 /febrero/1979

Señor Profesor

Dr. Domingo García Belaunde

Lima.-

Mi muy estimado amigo y colega:

Disculpe la demora en responder su gentil carta de fecha 26/XII/78 que recién puedo leer al encontrarla en mi casa con mi retorno a ella después del verano.

Lamento decirle que me es imposible satisfacer su deseo porque no tengo la ponencia MATEMATICA, FISICA, HISTORIA Y DERECHO que, según Ud. me dice, el Prof. Francisco Miró Quesada presentó al Congreso de Filosofía celebrado en Lima en 1951. Ni siquiera tenía noticias de esta presentación. Yo sólo recibí el paquete con las ponencias de la sección Filosofía del Derecho, donde Miró Quesada presentó una ponencia titulada LA LOGICA DEL DEBER SER Y SU ELIMINABILIDAD.

Por si su interés se refiriese a esta ponencia en la hipótesis de que a su respecto mediase únicamente una trascordación de título, debo decirle que, hace más o menos ocho años, recibí desde Lima el pedido de un profesor amigo (cuyo nombre se ha esfumado de mi memoria), solicitándome el envío de la ponencia aludida pues estaban en San Marcos con la tarea de editar todos los trabajos de Lógica de autores peruanos recientes. Y ocurrió que al solicitársela a Miró Quesada a este efecto, él reconociendo la paternidad de la misma presentada al Congreso de Filosofía de 1951, les contestó que no podía acceder por no haber guardado el texto de ella. El solicitante como entrelínea de su carta daba a entender que no creía en la sinceridad de la excusa de Miró Quesada. Pensaba más vale en una disconformidad de aquel como autor en el sentido de un cambio de opinión durante el tiempo transcurrido. Pero como para él se trataba de consolidar una documentación con plenitud y valor histórico, se agarró de la forma como se le excusó Miró, para solicitármelo a mi si yo poseía su copia oficial. 
Así fue que le remití mi copia, la cual se publicó en la revista de la Pontificia Universidad Católica del Perú, Sección Derecho, Número 30 (Lima 1972).

Aprovecho también esta oportunidad que me da una frase de su carta para manifestarle que no creo que el Prof. Miró Quesada "conozca muy bien a mi obra y a mí». Por el contrario, tengo la convicción y la evidencia de que nunca se ha hecho cargo debidamente de mi pensamiento, como requisito previo para marcar sus conocidas disidencias con mi falsificado pensamiento. Para ejemplificar aprovecho el agregado que el Prof. Miró Quesada ha colocado en el texto de su ponencia de 1951 en la publicación de la Rev. de la Pontificia Universidad Católica del Perú: El entiende que la conjunción "O" tiene dos acepciones lingüísticas (la «exclusiva» y la «inclusiva» definidas por la actual Lógica matemática) y nada más y a ellas él se atiene. Pero esta conjunción tiene en castellano cuatro acepciones legítimas reconocidas por la Gramática de la Real Academia. La tercera acepción es la de los sinónimos (v.g.: el burro o asno es un herbívoro). La cuarta acepción es la de la vida en su despliegue inmanente, que vemos ya en la vida biológica no obstante ser ello impersonal y sobre todo en la vida biográfica que muestra autoría y egología. No toco ahora el problema del nombre que yo doy a esta acepción, que nos sacaría del tema. Prefiero mostrar su alcance y el descarrilamiento que con motivo de ella comete Miró Quesada al embestir contra la formulación disyuntiva que el pensamiento egológico asigna a la norma jurídica. Esta cuarta acepción es la que utiliza la Teoría egológica al mostrar la estructura lógica de la norma jurídica, lo cual quita todo valor a la «refutación» de Miró mediante la evidenciación de una discusión ociosa, que no cabe en mi planteamiento por esta sencilla razón: Miró da por sentado e indiscutible que la enunciación egológica de la norma jurídica es una proposición «molecular» (usando el difundido y elocuente lenguaje de Russell, que es metafórico) y como consecuencia hace valer como trasfondo de su argumento, el cálculo proposicional que está aquí limitado por las dos únicas acepciones que la Lógica matemática utiliza, (con todo derecho y corrección, claro está, si estas dos acepciones resultan suficientes para abrazar todos los problemas de su limitado y peculiar lenguaje).

Pero según la tesis egológica, la norma disyuntiva que ella presenta es una proposición atómica; lo cual significa que ella está fuera del horizonte del cálculo proposicional. En tal caso Miró habría argumentado en vano, esto es, fuera de tiesto.

Ha sorprendido a los lógicos de la Lógica deóntica de Buenos Aires que yo me refiera a una proposición atómica, tratándose de una expresión 
verbal que exhibe dos verbos en modo indicativo. Pero nada menos que von Wright cuando abjura de su lógica deóntica inicial para poder afrontar la inclusión de la temporalidad en su -a mi juicio frustrada- Lógica de la Acción (o de la Conducta como es en el lenguaje egológico), aclara en forma similar que una expresión verbal que muestra tres verbos en modo indicativo, es en su actual pensamiento una proposición atómica (ver su Norm and Action, 1963; p., 47, cap. II, num. 7 de la traducción castellana Ed. -Tecnos, 1970).- Todo esto lo verá Ud. ampliamente desarrollado en la próxima edición de mi EL DERECHO EN EL DERECHO JUDICIAL que en el curso de este mes pongo en manos del editor.

Tampoco yo puedo reconocer a Miró Quesada ninguna clase de prioridad con relación al tema de la Lógica del deber ser. En el trabajo que publiqué en la "Revista de la Facultad de Derecho de México" (JulioDiciembre de 1973, № 87/88) que Ud. recuerda en su carta, dejé bien sentada la cuestión. Quien por primera vez usó las denominaciones de "lógica del deber ser» y "lógica normativa» desde 1941 hasta la fecha, fuí yo. (Ya está en el Prefacio de la traducción castellana de 1941 de $L a$ Teoria pura, los empleo innumerables veces en mi La Valoración juridica y la Ciencia del Derecho (1941) y en mi Teoria egológica del Derecho (1944). Aclaro allí en los mismos lugares desde 1941, que Kelsen ha sido el primero en ver, ya en 1911 , el nuevo territorio de un deber ser lógico, esto es, en "poner al descubierto, por primera vez, una esfera inédita en el campo del Derecho de vital interés: la esfera de la Lógica jurídica», como se puntualiza ya en el referido Prefacio). Este Prefacio parece haber sido el primer contacto de Miró con el tema de una lógica del deber ser, atenta a que él nos confiesa que el libro de Kelsen lo llevó a ello. Lástima que no aclare quien lo había informado que en La Teoría pura del Derecho «se desarrollaba una teoría profunda de la lógica jurídica». Si éste fue su primer contacto (la traducción castellana se la hice remitir yo como Presidente del Instituto Argentino de Fil. Jur. y Social, cuando apareció en 1941), sin duda leyó mal mi Prólogo o no lo leyó, pues yo no hablo de ningún desarrollo profundo de la lógica jurídica sino del horizonte de esa lógica en virtud del descubrimiento de una nueva cópula y nada más. A esta aserción mía la encuentra Ud. en mi ya citado artículo de la revista mexicana, pp. 451/52-hago esta aclaración porque lo encuentro a Ud. concediéndole a Miró una prioridad que no tiene, en su nota a la publicación de la Universidad Pontificia...) Y la volverá a encontrar en todas mis publicaciones, incluso en la próxima edición de EL DERECHO EN EL DERECHO JUDICIAL. Con esta aserción mía coincide también el propio von Wright -lo hice notar en la $2^{\circ}$ ed. de mi Teoría egológica..- subrayando la inexplicable tardanza de von Wright para conocer a Kelsen (1963, obra citada) y destacan- 
do que lo objeta con uno de los dos argumentos con que yo lo tengo objetado desde 1941 en relación al axioma ontológico de que en el Derecho, todo lo que no está prohibido,está jurídicamente permitido.

Y por último un breve comentario a otra frase de Miró en el agregado principal que ha introducido a su ponencia de 1951, a saber: «Fue para nosotros muy divertido observar el desconcierto que provocamos. Las respuestas de Cossio fueron más bien vagas...».

A mí también me divirtió mucho la intervención y la ponencia del Prof. Miró Quesada, pero no por su vaguedad sino por la incomprensión total del pensamiento egológico sobre la norma jurídica y la lógica del deber ser. No sólo me divirtió entonces sino que me sigue divirtiendo mucho todavía. Lo apreciará Ud. debidamente en la próxima edición de EL DERECHO EN EL DERECHO JUDICIAL. Según mi recuerdo lo que ocurrió en Lima en 1951 fue lo siguiente:

G. von Wright publicó, en enero de 1951 en la revista Mind. El primer despliegue sistemático recurriendo a la Lógica simbólica, de la Lógica del deber ser o Lógica normativa así bautizada por mí en 1941 y descubierta por Kelsen sin sospechar lo que él descubría, en 1911. Von Wright la denominó Lógica deóntica. También desde mi libro de 194l, yo proclamé la ceguera de Kelsen relativa a la naturaleza y alcance de su descubrimiento, con el siguiente slogan que alcanzó amplia difusión en la América Latina y en Europa: «hay que hacer kelseniano a Kelsen a pesar de Kelsen». Kunz la citó irónicamente en su libro sobre lo iusfilosofia latino-americana y se la comunicó a Kelsen, quien lo tomó como una humorada de mi parte al leerla en el libro de aquél; pero cuando Kelsen visitó Buenos Aires en 1949 y advirtió que la frase «iba» en serio, se irritó muchísimo conmigo, azuzado por la gente intelectualmente muy inferior que lo rodeó durante su permanencia entre nosotros.

Yo supe de la aparición del citado trabajo de Von Wright el mismo mes de enero de 1951 antes de su aparición, gracias a la noticia que de él me dió mi amigo epistolar, el Profesor finés Otto Brusiin. La grande y noble amistad epistolar que con él llevaba, la selló definitivamente él mismo con su singular libro El pensamiento jurídico (1950), del que hay traducción española, Ed. E.J.E.A., 1959.

Desde el 15 de marzo al 15 de mayo de 1951, yo efectué un seminario sobre el trabajo de von Wright, sirviéndonos de una traducción de él realizada por el Dr. Carrió y repartido en copias mimeográficas entre todos los concurrentes. Entre éstos estaba el Dr. Alchourrón en calidad 
de egresado, a quien conocí personalmente con tal motivo. El seminario se realizó en el Instituto de Filosofía de nuestra Facultad de Derecho y Ciencias Sociales.

Este seminario me convenció de la inutilidad absoluta para los juristas, jueces e investigadores del Derecho, de la lógica deóntica desarrollada por von Wright, así como también de su carencia de fundamento ontológico. Juicio que hoy mantengo con más convicción que antaño. Yo concebía el problema de otra manera desde que lo advertí en 1941. Lo he meditado permanentemente hasta 1967 en que pude resolver todas las dificultades que en él advertía. Esto retrasó la aparición de mi anunciado libro sobre Lógica jurídica. Pero anticiparé una suficiente reseña en la próxima edición de EL DERECHO EN EL DERECHO JUDICIAL; más larga y más completa que las dos con que expuse mi pensamiento en Brasil (en Salvador primero y San Pablo después) y en Buenos Aires cuando fuí repuesto en mi cátedra; y antes, en 1968, en la Universidad jesuíta de El Salvador.

Ahora bien; cuando en 1951 en el Congreso de Filosofía de Lima me encontré con García Máynez y Miró Quesada, no solamente de presencia, sino también con trabajos de ambos relativos a la Lógica del Deber Ser que había adquirido, al ser por mí bautizada, una enorme visibilidad (merecida o inmerecida no es lo que aquí ahora ni en el Congreso de Lima podía interesar circunstancialmente). Y mi situación era ésta:

Frente a García Máynez estaba nuestra discrepancia recíproca escrita en nuestras obras (libros y folletos) con varias réplicas y contrarréplicas. Yo había quedado al parecer con la última palabra largamente explayada en la Teoría egológica... (ed. de 1944). Después de este libro García Máynez había silenciado. Todavía García Máynez ni siquiera había reconocido -cosa que hizo algún tiempo después- su arbitrariedad de distinguir una acepción amplia y otra estricta del término técnico-jurídico "permitido", donde en sentido estricto los actos normativamente ordenados resultan ser lógicamente prohibidos, pero en sentido amplio son, al revés, lógicamente permitidos (ver Cossio, La Teoría egológica..., glosa № 22 a García Máynez). En esta situación personal, si él no aludía a nuestra polémica, sea para rectificar sus puntos de vista, sea para insistir en ellos, yo había resuelto no referirme para nada a la ponencia que él presentaba en la ocasión.

Y frente a Miró Quesada era su participación primeriza. Si esta entrada en escena era con conocimiento de mis ideas (sea para impugnarlas, sea para aceptarlas) yo me hubiese sentido obligado a decir algo de lo poco o mucho que tuviere para decir, como efectivamente tengo. Pero resultó que Miró Quesada estaba totalmente ausente de mi pensamiento. 
Así él manipuló en su ponencia la norma disyuntiva de la teoría egológica con el cálculo proposicional válido para las proposiciones moleculares, sin sospechar que se trata de una proposición atómica para las cuales semejante cálculo es impensable e improcedente. La conjunción «o» de que yo hablo, no es la conjunción «o» de que habla Miró Quesada. Para captar mi pensamiento en su planteamiento esencial hay que advertir que yo me refiero al logos de la conducta, en tanto que el pensamiento de toda la Lógica simbólica conocida se refiere al logos del lenguaje. Por eso desde la primera edición de mi Teoría egológica... he insistido en que me refiero al «yo actúo» trascendental de toda acción y no al «yo pienso» trascendental de todo juicio teorético-científico que tiene su propia legitimidad diferente.

Frente a esta doble situación, opté por limitar mi intervención en el debate de Lima a hacerles saber a ellos, que ese desarrollo sistemático que ellos exigían incluyendo el correspondiente cálculo proposicional, ya existía con el nombre de Lógica deóntica, que su autor era el hasta entonces desconocido lógico Georg von Wright y que se lo podía leer completo en el número de enero de la Revista Mind. Esto les provocó de verdad un desconcierto a los Prof. García Máynez y Miró Quesada que no estaban aún anoticiados de la novedad que les comuniqué. Y me fastidió un poco, es cierto, la violencia con que respondieron como dudando en alguna medida de la rigurosa verdad de mi información, reclamándome toda clase de datos concretos sobre la fecha y el contenido del artículo de Mind y sobre mi seminario relativo a ese artículo, pidiéndome una ratificación expresa de que no había ninguna exageración de mi parte en la noticia que les daba y que resultaba milagrosamente cabal para silenciar la exigencia condicionante de toda teorización sobre Lógica del deber ser, que ambos me reclamaron en algún momento; reclamo, por lo demás, para ellos atendible pero no para mí porque no compartía la adhesión que ellos daban a la Lógica matemática para los problemas del pensamiento jurídico y del Derecho.

Por eso me limité a decirles que no valía la pena discutir un problema que ya tenía una base que ellos reclamaban como necesaria pero que ellos todavía no conocían. Pero que aceptaba el debate para cuando ellos ya hubiesen leído el trabajo de von Wright. No creo que les cayó bien esta manera de cerrar un debate por mi parte sobre las ponencias de los dos distinguidos Profesores. Pero lo que no creo es que se pueda decir que mis respuestas fueron más bien vagas, como dice Miró Quesada en su agregado a su ponencia de antaño. Sería interesante que aclarase dónde estuvo la vaguedad.

Por lo demás dejé en claro que si bien yo concordaba con von Wright en el carácter copulativo-lógico del "deber ser" que él tematizaba for- 
malmente, sistemáticamente y combinatoriamente, reputaba errada su tesis de que esto fuese una auténtica lógica del deber ser adecuada para los problemas del Derecho y de la Jurisprudencia como ciencia. Que mi pensamiento era otro y que estaba dedicado a meditarlo a fondo. Y que cuando hubiera terminado esta tarea, sea en forma afirmativa para mi intuición inicial, sea en forma negativa, se los haría saber. Lo que nunca pensé es que esta meditación duraría en mí hasta 1968 para ver recién el comienzo de una verdadera solución y que me iba a complicar con una superación axiológica desconocida; con un replanteo total del problema de la razón práctica que comenzaba por eliminar a Aristóteles y a Kant de esta problemática; y con una fundamentación ontológica del logos de la conducta diferente a la del logos del lenguaje, que esclarecería recién y del todo qué es esto de una lógica de la conducta y cual es su trascendencia práctica.

Y con esto cierro esta carta que aunque excesivamente larga, me sospecho que habla de lo que Ud. precisamente estaría deseando que yo hablase, así fuere para oir a la otra parte que en esta emergencia soy yo.

Esperando sus noticias, lo saluda muy cordialmente su amigo,

\section{Cossio}

P.S.- Todavía no me ha llegado el pequeño libro que me anuncia Ud. haber despachado juntamente con la carta que contesto.

Vale.-

Como he anotado, la carta es muy ilustrativa, y en términos generales, creo que podrían hacerse dos distingos: $\mathrm{ca}, \mathrm{y}$

a) La explicación que da Cossio sobre su concepto de la lógica jurídi-

b)Su versión sobre lo que pasó en aquel Congreso.

En cuanto al primer aspecto, creo que ya hemos dicho cuál es nuestra opinión sobre el planteo cossiano. Pero en cuanto a lo segundo, o sea, la descripción de lo sucedido en 1951, creo que Cossio da rienda suelta a su imaginación y dice cosas que no se compadecen con los hechos, y que deben ser tomadas cum grano salis. Así, por ejemplo:

i) Es más que dudoso que en julio de 1951, Cossio estuviese fami- 
liarizado con el pensamiento de von Wright, pues nada hay que demuestre que así lo sea. Lo cita por vez primera y muy de pasada en su libro Teoría de la verdad jurídica, que es de 1954, sobre la base de unas conferencias impartidas en México y en 1952, por lo que es de suponer que tomó conocimiento de von Wright a fines de 1951.

ii) Es muy improbable que Otto Brusiin le haya enviado los originales del texto de von Wright. En primer lugar, Brusiin sólo intimó con von Wright años después; en esa época, Brusiin estaba en Helsinski y von Wright en Cambridge. Aún más, es difícil decir que la amistad epistolar entre Brusiin y Cossio, fuera sellada con la traducción de la obra de éste al castellano en 1959, titulada El pensamiento jurídico. En esta obra, Brusiin da cuenta del pensamiento de Cossio, un poco al pasar y sin participar en él; y en el prólogo que especialmente prepara para la edición castellana, menciona a varios juristas de habla hispana, pero silencia a Cossio.

iii) Es también muy improbable que del 15 de marzo al 15 de mayo de 1951 haya dado todo un seminario sobre el texto de von Wright. En primer lugar, el texto de von Wright era de 15 páginas y muy incipiente y seguramente no daba para un seminario; y además estaba salpicado de simbolismo, que era ininteligible para Cossio, que no tenía nociones de lógica matemática. Además, de la información que hemos recabado de algunos asistentes a dicho seminario, no se desprende nada de lo que Cossio afirma. Y el mismo Cossio, en su texto La norma y el imperativo en Husserl, versión revisada de 1960, al dar cuenta del programa de su curso en Buenos Aires en 1950 y en 1951, así como de las lecturas ahí repartidas, no hace mención alguna a von Wright.

En síntesis, la posición de Cossio era distinta, lo que era de por sí respetable, pero sorprende cuando trata de demostrar que estaba al tanto de todo, lo cual, aun cuando deseable, no siempre es posible. En cuanto a von Wright, su importancia para el Derecho es apreciada en fecha muy posterior, y en el ámbito latinoamericano, si bien conocido probablemente en el curso del año $195 \mathrm{l}$, es analizado en forma años después: García Máynez lo hace en 1953, Cossio marginalmente en 1954 y Miró Quesada y otros, con más detalle, a partir de 1955.

Finalmente, hay que lamentar que, la anunciada versión definitiva de El Derecho en el Derecho judicial, nunca fuera publicada.

\section{Cossiana}

A Roberto J. Vernengo le escribí en abril de 1996, una breve carta, pi- 
diéndole información sobre el asunto de la lógica jurídica, en especial, con lo sucedido en la década del cincuenta, en la cual él frecuentaba el círculo de Carlos Cossio. Al no recibir respuesta suya, reiteré mi carta, que me fue contestada cl 4 de febrero de 1997, cuando yo ya había concluído la redacción de mi ponencia, y que, en sustancia, coincide con lo que yo había expuesto ahí. Si bien me he cuidado de obtener diversas versiones sobre los sucesos de 1951, tan sólo en el caso de Vernengo he obtenido una amplia como minuciosa descripción, que encuentro de sumo interés. Por eso es que la reproduzco, ya que, por haber sido su autor un cossiano de las primeras horas, aporta informaciones que, sin lugar a dudas, son de primera mano. El texto es el siguiente:

Buenos Aires, 4 de febrero de 1997

Estimado García Belaunde:

Acabo de recibir una copia de carta suya de abril del año pasado. Puede haber sucedido que se haya extraviado el original, pues estuve viviendo fuera de mi casa durante los primeros meses del año, porque tuve que hacerle reparaciones importantes, y el correo se hizo medio errático o fue recibido por obreros no demasiado responsables. Pero, bueno, paso a contestarle.

El trabajo de Cossio sobre «Las posibilidades de la lógica jurídica según la lógica de Husserl» es el resultado de un seminario, en el que participé, que desarrolló Cossio en 1949 ó 1950. Que yo recuerde no se encaró entonces problema alguno de lógica modal -que era terreno incógnito-, ni se trató del ensayo de von Wright, que sólo apareció en 1951 . Es verdad, si, que cuando, en 1951 se publicó ese trabajo en «Mind»que llegó a Buenos Aires pocos meses más tarde, Cossio nos advirtió a todos sobre la necesidad de estudiar algo que era novedoso. Me parece que todo eso fue más o menos simultáneo con el congreso de Lima y la polémica con Miró. Tanto von Wright como Klug conocieron el trabajo de Cossio sobre Husserl, pero muchos años después; le diría que en los años sesenta. Pienso ahora que Cossio no podía entender los desarrollos formales de von Wright. Por cierto que también tuvo noticia del trabajo de Kalinowski en "Studia Logica», que le envió el autor.

Ahora, en cuanto al background filosófico, quisiera recordarle que en los medios egológicos de ese entonces (yo me fuí a vivir a Ginebra a fines del 5l), que conocí muy bien por tratar cotidianamente a Cossio y a Gioja, lo que se llamaba "lógica» era una disciplina vista con ojos neokantianos: el texto que se consideraba rector era la lógica de Pfänder (iimagine usted!) y, filosóficamente, se pensaba que las Investigaciones 
Lógicas y Lógica formal y trascendental (que circulaba en una traducción local interna hecha por E. Langfelder) constituían el non plus ultra de lo que hoy consideraríamos meta-lógica. Por mi parte, recuerdo mi sorpresa cuando, con Gioja y ya en Europa, leí el original de los Logische Untersuchungen y advertí que la traducción española-catalana que manejábamos, distorsionaba enormemente el pensamiento -no demasiado claro- de Husserl, pues ignoraba la existencia de una lógica proposicional clásica. Véase la traducción arbitraria de Satz, por cierto un término ambiguo. Cossio, hasta ese entonces, no tenía noticias de las lógicas postfreguianas, y de los desarrollos en lógicas modales. Fue a partir de 1951 que, los que habíamos sido discípulos de Cossio -Carrió, Alchourrón, Bulygin y yo mismo- comenzamos a estudiar lógicas más al día; casi todos empezamos con el manual de Tarski. Con Gioja nos pusimos a la tarea de abordar Principia. También conviene advertir que, en Europa, las cosas estaban en muchos países más o menos en similar situación. Heidegger, por ejemplo, aunque sabía de la existencia de Frege y Russell (y de Wittgenstein, seguramente), pasaba por alto los desarrollos lógicos acaecidos desde principios de siglo y repetía que lógica era el pensamiento sobre el logos en Heráclito (también participé en uno de esos seminarios). Y no hablemos de Francia, donde en derecho tales cosas eran enteramente ignoradas. Bobbio - con quien Cossio mantenía correspondencia frecuente- es típico al respecto; es sólo en la década del 50 que se anoticia cabalmente de los problemas del lenguaje y de las lógicas. Algo similar pasó con Klug y García Máynez que sólo por entonces tomaron noticia de las novedades lógicas. De ahí que, en Buenos Aires al menos, al regresar Gioja (yo volví en 1957), en la Facultad de Derecho, se estudiara Wittgenstein (el primer seminario a mi cargo fue sobre el Blue Book), Carnap (de quien se ocupó Alchourrón) y quedara abierto el aluvión analítico. Por lo que sé, Cossio ya no participó en tales desarrollos.

La situación de Miró es algo especial, me parece. Sus intereses, desde un principio, estuvieron en problemas de fundamentación de las matemáticas y los desarrollos lógico-jurídicos fueron para él un poco marginales. De ahí que no se entendieran realmente con el Cossio de 1951, pero también que se sorprendiera con los desarrollos que la filosofía analítica del derecho tuviera en Buenos Aires en la década siguiente, desarrollos que consideró imposibles en un país del III mundo, como quería ver a la Argentina. El asunto es curioso; el libro de Atienza, que Miró prologó, cuenta un poco el cuento, pues también en España, que seguía recitando monsergas neoescolásticas, esta línea analítica en el Río de la Plata era inédita. Casi todos los textos ahora son fácilmente obtenibles; las obras completas de Alchourrón están publicadas. Entre las que quedaron inéditas, por ser de interés menor, figura un curso de lógica de 1959, que escribimos juntos en parte; un curso importante so- 
bre lógicas modales en Lukasievicz que dictó por la misma fecha Klimovosky; y un curso sobre semánticas extensionales que dictó Raggio. Mi primera publicación a mi vuelta a la Argentina, también aplica procedimientos de decisión extensionales para intervenir en una polémica que Cossio mantenía en pie sobre la forma lógica de las normas jurídicas, asunto que hoy nos parece mal planteado. Pero todo esto es, realmente, historia antigua.

Quedo a su disposición para cualquier aclaración.

Cordialmente

Roberto J. Vernengo 